\title{
Theoretical Analysis of Enterprise Financial Management Mode
}

\author{
Haohao $\mathrm{Li}^{1}$, Nan Zhou ${ }^{2}$ \\ ${ }^{1}$ Jiangxi Institute of Economic Administrators, Nanchang, Jiangxi, 330038 \\ 59624917@163.com
}

Keywords: Enterprise Financial Management; Financial Flow; Stocks

\begin{abstract}
This paper mainly targets SMEs in China, explores the contents of corporate financial management, constitutes a mode of analysis of the environmental impact of financial management and selection method. The system analyzes the status quo of enterprise financial management mode and problems, and proposed improvement and development of enterprise financial management strategies.
\end{abstract}

\section{Introduction}

Financing means to raise funds. For example, companies issuing shares, bonds, obtain loans, credit, lease financing belong. Financing the management to solve the problem is how to obtain the required funds business, including to whom, at what time, raise How much funding. funding decisions and investments, dividend distribution is closely related to the amount of financing investment needs to consider how, in the distribution of profits to increase retained earnings can reduce external financing from key funding decisions is to determine the various sources of funding in total funding the proportion that determine the capital structure, in order to make the financing risk and financing costs mate.

Investment refers to cash and cash take place in order to recover and get the benefit for the purpose of the outflow. For example, the purchase of government bonds, corporate stocks and bonds to buy, build factories, adding new products, enterprises should a currency outflow, and expect to get more The cash inflow of investment management is the basic content of investment decision analysis, but in its complete sense, the primary task is to select investment management direction of investment, such as diversified investment, integrated investment and specialized investment because the investment direction Problem different options means that companies in different development direction and path, so the choice of investment direction is a very strategic, you must be cautious. In particular investment decision analysis, on the one hand to carefully settlement cash flow, on the other hand also take full account of investment risk in investment projects after the formation, but also pay attention to strengthening the tracking and management, in order to ensure that the investment project implementation process to achieve the desired effect.

Dividend refers to profits earned in the company, how many as a dividend to shareholders, how many remain in the company as a re-investment. High dividend payout ratio, affect the ability of enterprises to invest and make the companies to reduce future earnings, cause fell; low dividend payout ratio, it may cause dissatisfaction of shareholders, the stock will fall dividend policy, from another perspective also retained earnings decision is an internal problem of financing enterprises.

Working capital is the sum of current assets to current liabilities relations and, in Canada the sum total here is not the amount, but rather reflects the relationship, which is conducive to financial officers realized that the management of working capital to pay attention to current assets and current liabilities of these two issues. the basic task of working capital management is to raise short-term cash flow and efficiency of short-term funding sources. the basic goal of working capital management is through the effective daily scheduling and transfers of funds, a reasonable allocation of funds to raise capital use efficiency, and enhance liquidity. 


\section{Financial Management Model and Its Characteristics}

Financial management refers to the managers of financial management under the guidance of a certain ideology, corporate financial management objectives, financial management objects and methods to integrate financial management in order to promote effective financial management activities, a reasonable management of state operations. Management activities in the adopt a comprehensive reflection of the financial structure, financial management practices, financial management tools, etc., and its essence is the effective operation of the enterprise capital to achieve corporate financial management objectives. Financial management should be designed to consider the business size, industry characteristics, business type and other factors, should help improve financial management efficiency.

According to the characteristics of the modern enterprise, financial management should be the following parts:

Financial management concepts, namely the concept of corporate financial management, is the basic idea of the basic concepts and working process of the formation of financial awareness, it reflects the stand, viewpoint and method of financial managers, is an important foundation for enterprise financial management, the contents of corporate financial management, methods and quality of the work has an important impact.

The fundamental idea refers to the most basic of financial management process, the formation of the financial management and use of instructive ideas, such as the system concept, the concept of balance, elastic concept, optimization philosophy, etc. The core idea is the concept of financial management refers to the process of applying various methods must hold, which determines whether financial management practices can be correctly used, such as the concept of time value of money, risk and benefit ratio concept, philosophy and other capital costs. business concept refers to the use of a particular method in a particular area of financial management in selected corporate philosophy, these ideas only for certain types of financial management activities and play a role, capital structure and financial concepts such as financing when Leverage concept, portfolio concept and the concept of operating leverage investments in enterprise operational control of the cash flow concept, choice of capital structure and distribution policy concept idea when distribution policy and so on.

Scientific concept of financial management with the times, and is constantly changing to adapt to the financial management of the environment, it can make enterprises in the new period of development to seize the opportunity to promote the sustainable development of enterprises.

Financial management objectives, also known as financial goals, corporate financial activities to achieve the fundamental purpose is to evaluate the reasonableness of enterprise financial activities of basic standards, which determine the basic direction of financial management. Financial management objective is a target by the overall objectives, division Purpose and targets constitute the overall goal of the entire enterprise financial management objectives to be achieved, that is, we usually refer to the financial management objectives, which determines the division of goals and objectives, is the starting point and destination of financial activities. Segment target is under the constraints of the overall target, a part of the financial activities for target to be achieved, such as fund-raising goals. Target is under the constraints of the overall goals and objectives of the division, engaged in a specific financial activity to be achieved target, such as a particular borrower to achieve the goal, the end result of the overall goals and objectives of the division.

Financial relationships resulting economic relations companies in financial activities and among relevant stakeholders can be summarized as five aspects: financial relationships between companies and financial relationships between donors, companies and creditors, business and Country manager of Administrative Services as a financial relationship between the financial relationship between business and financial relations between the main market transactions and enterprise. section between the various departments of reasonable scientific enterprise can regulate the financial relationship model of modern financial enterprises relations, in particular internal financial relationships. 
Financial accountability is the right and responsibility to regulate corporate financial management units at all levels (staff, organization), and is referred to the financial management rights and responsibilities reasonable financial accountability model should allow the right to financial management at all levels of the enterprise and responsibilities are very clear, so fulfill their duties, and fully mobilize the enthusiasm.

\section{Financial Management Problems in Current Enterprises}

SMEs in setting up financial management objectives, either in terms of profits as the goal, or is for other enterprises blindly follow, imitate, did not understand the financial management objectives will be affected internal and external environment, the choice of financial management objectives should be considered various factors, pure imitation is not enough.

In addition, since the owners of SMEs often also is the manager of the enterprise's main decision-making, including financing, investment, distribution and other decisions made by the owner manager. Owner manager in real life, as a natural person, not only the physical aspect of the goal, Sometimes the role of objective spirit in the financial management of enterprises in the decision-making played even bigger than material goals. For example, the main objective of some sole proprietorship or family business is to solve the employment problem, they No, and the environment does not allow them to profit maximization as its main objective pursued, which would bring long-term development obstacles.

SMEs in China, especially in the financial decision-making power of the family business tends to be concentrated in the hands of a small number of senior managers, investment, funds transfer, financing and financing payments are made daily financial business major leaders personally approved, this management responsibilities regardless of the control program, which greatly restricted the play of financial management functions.

In the financial management activities, the degree of centralization can make limited financial resources to get the best control and configuration under the supervision of senior managers, but it will make too much concentration of power in accordance with the financial staff can not make timely information available the corresponding decisions, lack of flexibility.

\section{Strategies to Improvement a Enterprise Financial Management}

In order to effectively overcome the centralization of business leaders, the evils of family management, and promote the development of deeper, owners and managers of SMEs must enhance learning, effectively change the financial management philosophy, and establish financial management is the core of enterprise management philosophy. should strengthen the implementation of financial management as an important part of the SME management system, implement the various functional departments within the enterprise. In addition, China should establish a people-oriented SMEs, diversification of risk financial management concepts, in order to adapt to the new financial environment.

Determine the scientific and clear financial management objectives, both the inevitable requirement of the development of SMEs, is also an objective environment for our small and medium business financial behavior constraints. Sound financial management objectives should not only reflect the objective laws of SME financial activities, but reflect the requirements of the macroeconomic system and business methods, objectivity, comparability, operability, and focus on unity solvency, operating capacity and profitability. Specifically, as a corporate effective financial management activities of the premise, A sound financial management objectives shall comply with the following characteristics: measurability, consistency, phased and integrated according to China's actual situation, the profit maximization objective of sustainable development is suitable for the majority of our financial management of SMEs at the present stage. mode, which solves the problem of the development of SMEs in the financial aspects of the process.

Organization theory point out that the organizational structure of enterprises according to their different responsibilities and interests between the internal structure, can be divided into many types 
of $\mathrm{H}$ type, U, M-type, etc. of SMEs to improve and perfect the financial organizations, should be based on the company development strategies and development stage, to define the functions of the financial organization, financial organization and a reasonable set of positions management to enhance the smooth transition; the status and business process convergence, consolidation accounting processes, a clear accounting of the entire process and financial management focus, so that clear responsibilities and rights of financial officers, business people and senior managers at all levels between the organization and management to improve the efficiency, effectiveness; develop financial base management system, standardize financial work.

The choice of financial accountability relationship, certainly not carried out in centralized or decentralized decision-making model in a simple choice, but to the right of effective control, so adjust a degree, coordinated and effective. Our financial power for SMEs too focused on the phenomenon of responsibility, should a reasonable set of financial management hierarchy and management range, choice and enterprise management agencies adapt financial management system, appropriate delegation of financial management authority, business executives should only make decisions on major matters, and the power and Responsibility peering, and make sure who is responsible for who perform, give full play to the functions of financial management. Since decentralization, so that financial officers from passive actors into participants in the decision making, this approach will not only be able to overcome the SME Finance decision-making power is too concentrated drawbacks, but also improve the efficiency of decision-making on the changing market information to respond quickly to seize those unexpected opportunities.

\section{Conclusion}

Financial management refers to the managers of financial management under the guidance of a certain ideology, corporate financial management objectives, financial management objects and methods to integrate financial management in order to promote effective financial management activities, a reasonable management of state operations. Financial management major by the concept of financial management mode, target mode of financial management, financial relations model, financial accountability mode, the operating mode of the five sub-modes financial constitution in which the financial and operating modes including setting financial organization, financial information communication mechanism, financial management and control mechanisms financial incentives.

\section{References}

[1] Wen-Qiu F, Wang-Jian Q, L. Measuring the Ability of Enterprise Financial Management. Western Circles Culture, 2009 (1): 37-43.

[2] Wang Bing, Gao Chen. Organization Design Management and Control System and Financial Institutional Arrangements. Accounting Research, 23,3:. P15-22.

[3] M.Blair. Owner Ship and Conrtol: Rethinking Corporate Govenranee for Thetwenty-First Century. Brookings Institution,1995. 